\title{
Leaching Mo and Ni by Direct Oxygen Pressure from Black Shale with any other only water
}

\author{
DENG Zhi-gan", a, WEI Chang1', LI Xing-bin', LI Cun-xiong1, FAN Gang1 \\ ${ }^{1}$ Faculty of Metallurgical and Energy Engineering, Kunming University of Science and Technology, \\ Kunming 650093, China \\ aemail: dengzhigan83@163.com
}

\begin{abstract}
Keywords: Black Shale, Molybdenum and Nickel, Oxygen Pressure Water Leaching
Abstract. The hydrometallurgical process of leaching molybdenum and nickel from black shale without reagent was investigated. The extraction of Mo and Ni from molybdenum-nickel ore by oxygen pressure leaching, which exploit the characteristic of molybdenum-nickel minerals contain high concentration amorphous sulfide which has highly active, and make the most of easily oxide to sulfuric acid and sulfate at low temperature and excess oxygen presence of the amorphous sulfide. Under oxygen pressure conditions, considerable molybdenum and almost all the nickel were extracted into solution in the leaching process. The results show that with the leaching time for 3 4h, temperature at $150^{\circ} \mathrm{C}$, liquid-to-solid ratio of $2 \mathrm{~mL} \cdot \mathrm{g}^{-1}$, mineral granularity of $0.074 \mathrm{~mm}$, oxygen partial pressure of $0.4 \sim 0.5 \mathrm{MPa}$ without other reagent, molybdenum leaching percentage can be over $80 \%$ and nickel leaching percentage can be more than $97 \%$. Furthermore, about $80 \%$ sulfur in the Mo-Ni ore has been transformed into sulfuric acid.
\end{abstract}

\section{Introduction}

The black shale is an important molybdenum and nickel source, which as a sediment-hosted ore layer of the lower Cambrian black shale has been known to local geologists for at least 50 years in China[1-2]. Apartial evaluation of the Mo-Ni ore deposits and their genesis has been attempted in past decades [3].

The Mo-Ni ore contains more than $4 \mathrm{wt} \% \mathrm{Mo}$, at least $2 \mathrm{wt} \% \mathrm{Ni}$, up to $2 \mathrm{wt} \% \mathrm{Zn}, 2.5 \mathrm{wt} \%$ As and $1 \sim 2 \mathrm{~g} / \mathrm{t}$ of precious metals, primarily $\mathrm{Au}, \mathrm{Pt}, \mathrm{Pd}$, and Os. The classic process for molybdenum and nickel recovery is roasting, melting and concentration to produce a high impurity nickel-molybdenum alloy. In the process, sulfur dioxide $\left(\mathrm{SO}_{2}\right)$ and arsenic trioxide $\left(\mathrm{As}_{2} \mathrm{O}_{3}\right)$ release may cause serious environmental pollution. Mineral processing routes have been proposed for the Mo-Ni ore[4], however, it is inefficient to enrich nickel and molybdenum through ore-dressing owing to the ore's complex mineralogical characteristics.

Several combined pyro-hydrometallurgical methods have been proposed to recover molybdenum from the Mo-Ni ore, such as roasting, $\mathrm{NaOH} / \mathrm{Na}_{2} \mathrm{CO}_{3}$ leaching under active oxygen conditions [5], direct leaching with $\mathrm{NaOH}+\mathrm{Na}_{2} \mathrm{CO}_{3} / \mathrm{NaClO}_{3}$ [6], direct $\mathrm{NaOH}$ leaching under active oxygen conditions [8] and direct leaching with $\mathrm{H}_{2} \mathrm{SO}_{4}$ for nickel recovery only [8]. Moreover, direct bioleaching of molybdenum and nickel from the Mo-Ni ore has been investigated using a molybdenum-resistant thermophilic bacterium sulfolobus metallicus, but the percentage leached is not very high and requires further research[9].

In this paper, a direct hydrometallurgical process of extraction molybdenum and nickel from molybdenum-nickel ore by pressure water leaching without reagent was studied. Various characteristics of the Mo-Ni ore are used beneficially and partial sulfur is transformed into sulfuric acid under oxygen pressure. The extraction of Mo and Ni from molybdenum-nickel ore by oxygen pressure leaching, which exploit the characteristic of molybdenum-nickel minerals contain high concentration amorphous sulfide which has highly active, and make the most of easily oxide to sulfuric acid and sulfate at low temperature and excess oxygen presence of the amorphous sulfide. 


\section{Experimental}

\section{Materials}

The chemical compositions of Mo-Ni ore of black shale was listed in Table.1. The XRD pattern of the raw Mo-Ni ore was shown in Fig.1. It was confirmed that the Mo-Ni ore consists crystalline pyrite $\left[\mathrm{FeS}_{2}\right]$, quartz $\left[\mathrm{SiO}_{2}\right]$, calcite $\left[\mathrm{CaCO}_{3}\right]$, millerite $[\mathrm{NiS}]$, elemental sulfur. Nickel occurs mainly as vaesite $\left[\mathrm{NiS}_{2}\right]$, millerite $[\mathrm{NiS}][10-11]$.

Table. 1 Chemical compositions of the Mo-Ni ore

\begin{tabular}{llll}
\hline components & wt.\% & components & wt.\% \\
\hline $\mathrm{Mo}$ & 6.89 & $\mathrm{CaO}$ & 8.52 \\
$\mathrm{Ni}$ & 4.73 & $\mathrm{MgO}$ & 0.82 \\
$\mathrm{~V}$ & 0.17 & $\mathrm{P}$ & 0.82 \\
$\mathrm{Fe}$ & 15.85 & $\mathrm{~F}$ & 0.085 \\
$\mathrm{~S}$ & 25.86 & $\mathrm{Cu}$ & 0.24 \\
$\mathrm{C}$ & 9.7 & $\mathrm{Zn}$ & 0.38 \\
$\mathrm{SiO}_{2}$ & 13.5 & $\mathrm{Ti}$ & 0.21 \\
$\mathrm{Al}_{2} \mathrm{O}_{3}$ & 2.86 & $\mathrm{~Pb}$ & $<0.05$ \\
\hline
\end{tabular}

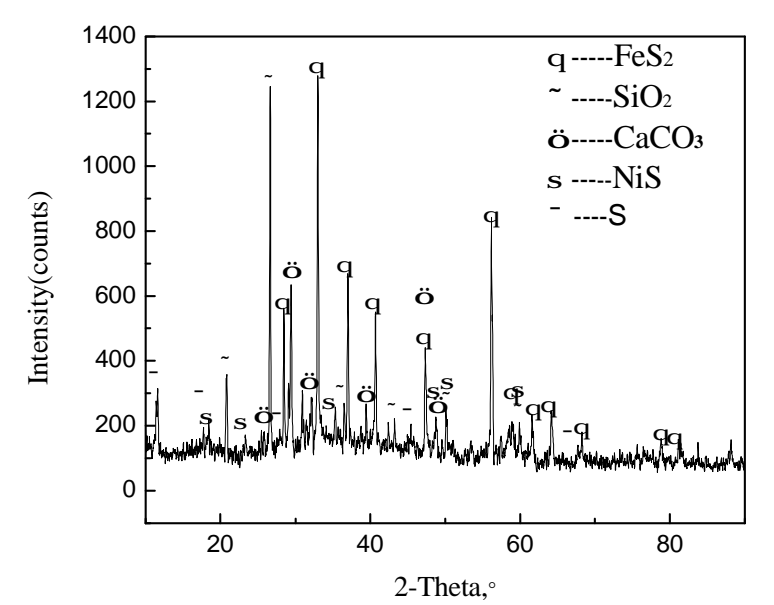

Fig. 1 XRD pattern of the Mo-Ni ore

The diffraction peak of the molybdenum (6.89\%) was not detected in the XRD pattern, which occurs mainly due to in the form of amorphous sulfide, which was confirmed that molybdenum primarily exists in the form of jordisite $\left[\mathrm{MoS}_{2}\right]$ in the Ni-Mo ore, and co-exists with clay, quartz .

\section{Experimental procedure}

The samples were crushed and ball milled to $85 \%<0.074 \mathrm{~mm}$ and dried at $75^{\circ} \mathrm{C}$ in an oven for 24 h. Leaching experiments were conducted at an oxygen partial pressure of $0.4 \sim 0.5 \mathrm{MPa}$ in an autoclave with 2L titanium alloy cylinder reactor.

\section{Analytical methods}

The metal contents of the raw ore sample and leaching residues were analyzed by ICP-AES (SPECTROBLUE, Germany), and X-ray diffraction (D/max 3B, Japan) to determine the phase of molybdenum and nickel.

The solution was analyzed by atomic absorption spectrometry (WFX-110B, Beijing) to determine the content of the chemical compositions, and the $\mathrm{pH}$ of the leaching liquor was measured using a digital $\mathrm{pH}$ meter (PHSJ-5D, Shanghai). 


\section{Results and discussion}

\section{Effect of leaching time on extraction}

The effect of leaching time on the extraction of molybdenum and nickel was studied under the conditions of the reaction time was varied between 3 and 9 hours, in 2 hours intervals. As shown in Fig. 2, the extraction of nickel increases strongly with the increase in leaching time from 3 to 5 hours at $150^{\circ} \mathrm{C}$ with a liquid to solid $(\mathrm{L} / \mathrm{S})$ ratio of $2 \mathrm{~mL} \cdot \mathrm{g}^{-1}$, and oxygen partial pressure of $0.4 \sim 0.5 \mathrm{MPa}$, 97\% nickel extraction was obtained in 5 hours without sulfuric acid. This is probably because the nickel sulfide oxidizes to $\mathrm{NiSO}_{4}$, which dissolves easily into the acid solution under such conditions. Therefore, 5 hours is sufficient for nickel extraction. While the extraction of molybdenum increases gradually with an increase in leaching time from 3 to 5 hours, a maximum extraction of $76 \%$ is reached at 5 hours. Therefore, to obtain high nickel and molybdenum recoveries, in subsequent experiments, the leaching time was chosen to be 5 hours.

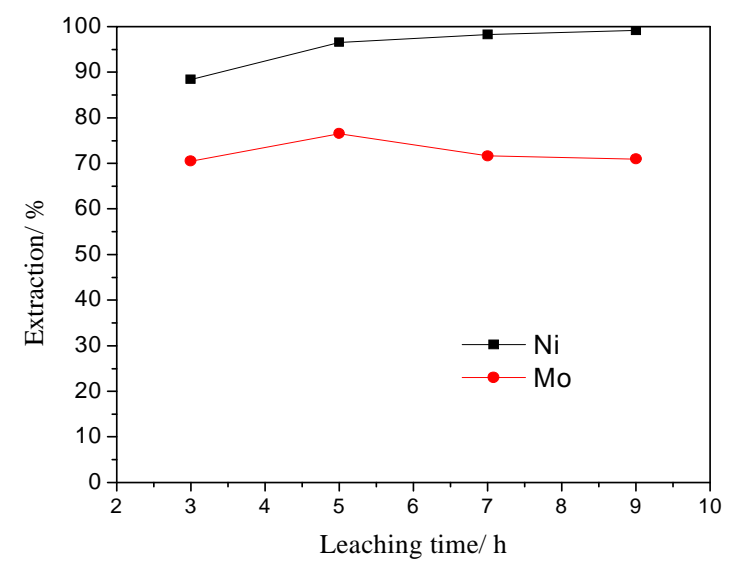

Fig. 2 Effect of leaching time on extraction

\section{Effect of leaching temperature}

The effect of temperature on molybdenum and nickel extraction was investigated from 105 to $165^{\circ} \mathrm{C}$ with distilled water, under an oxygen partial pressure of $0.4 \sim 0.5 \mathrm{MPa}$, and a liquid-to-solid(L/S) ratio of $2 \mathrm{~mL} \cdot \mathrm{g}^{-1}$ for 5 hours without sulfuric acid. It can be seen from Fig. 3 that nickel extraction increases with increase in leaching temperature from 105 to $150^{\circ} \mathrm{C}$. Beyond $150^{\circ} \mathrm{C}$, the extraction of nickel increases slowly with an increase in temperature. Molybdenum extraction increased with increasing temperature and increased only slightly beyond $150^{\circ} \mathrm{C}$.

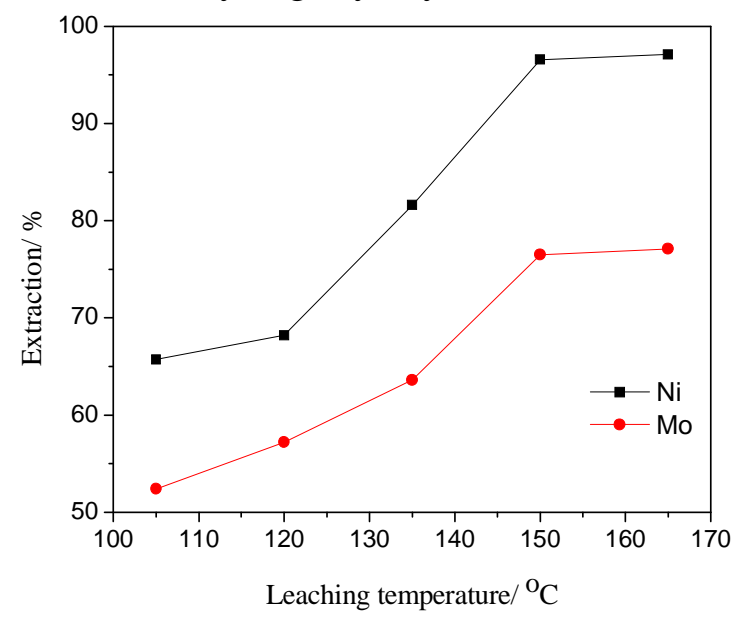

Fig. 3 Effect of leaching temperature on extraction 


\section{Effect of liquid-to-solid ratio on extraction}

The effect of liquid-to-solid ratio on molybdenum and nickel extraction was examined at an oxygen partial pressure of $0.4 \sim 0.5 \mathrm{MPa}$, and temperature of $150^{\circ} \mathrm{C}$ for 5 hours without sulfuric acid. A series of experiments were carried out by varying the liquid-to-solid ratio in the range of 1.5 to 6 $\mathrm{mL} \cdot \mathrm{g}^{-1}$. It can be seen from Fig. 4 that nickel extraction decreases slightly from 98 to $96 \%$ with increasing in liquid-to-solid ratio from 1.5 to $3.0 \mathrm{~mL} / \mathrm{g}$ and decreases sharply with increase in liquid-to-solid ratio from 3.0 to $6.0 \mathrm{~mL} \cdot \mathrm{g}^{-1}$. Molybdenum extraction decreases slowly from 76 to $75 \%$ with increase in liquid-to-solid ratio from 1.5 to $2.5 \mathrm{ml} \cdot \mathrm{g}^{-1}$ and also decreases sharply with increase in liquid-to-solid ratio from 3.0 to $6.0 \mathrm{~mL} / \mathrm{g}$. The extraction of molybdenum and nickel decreases sharply with increase in liquid-to-solid ratio from 3.0 to $6.0 \mathrm{~mL} \cdot \mathrm{g}^{-1}$. Considering various other factors such as agitation and pipe-line delivery in industrial plants, in subsequent experiments, the leaching liquid to solid(L/S) ratio was chosen to be $2 \mathrm{~mL} \cdot \mathrm{g}^{-1}$.

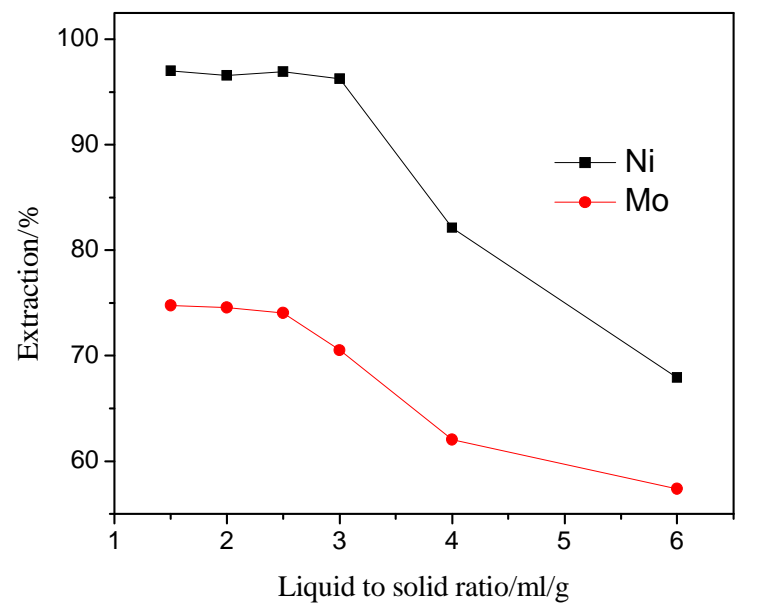

Fig. 4 Effect of liquid-to-solid ratio on extraction

\section{Characterization of the leaching residue}

The acid leach residue used in this study (composition in Table 2) was obtained after oxygen pressure leaching. Almost all nickel and a substantial part of the molybdenum were leached. The leaching rate of nickel and molybdenum achieve respectively $97 \%$ and $80 \%$.

Table. 2 Chemical compositions of the acid leach residue

\begin{tabular}{llll}
\hline components & wt.\% & components & wt.\% \\
\hline $\mathrm{Mo}$ & 3.16 & $\mathrm{CaO}$ & 12.46 \\
$\mathrm{Ni}$ & 0.45 & $\mathrm{MgO}$ & 0.13 \\
$\mathrm{~V}$ & 0.024 & $\mathrm{P}$ & 1.14 \\
$\mathrm{Fe}$ & 5.21 & $\mathrm{~F}$ & 0.076 \\
$\mathrm{~S}$ & 10.5 & $\mathrm{Cu}$ & 0.044 \\
$\mathrm{C}$ & 13.2 & $\mathrm{Zn}$ & 0.055 \\
$\mathrm{SiO}_{2}$ & 20.91 & $\mathrm{Ti}$ & 0.23 \\
$\mathrm{Al}_{2} \mathrm{O}_{3}$ & 1.83 & $\mathrm{~Pb}$ & 0.24 \\
\hline
\end{tabular}




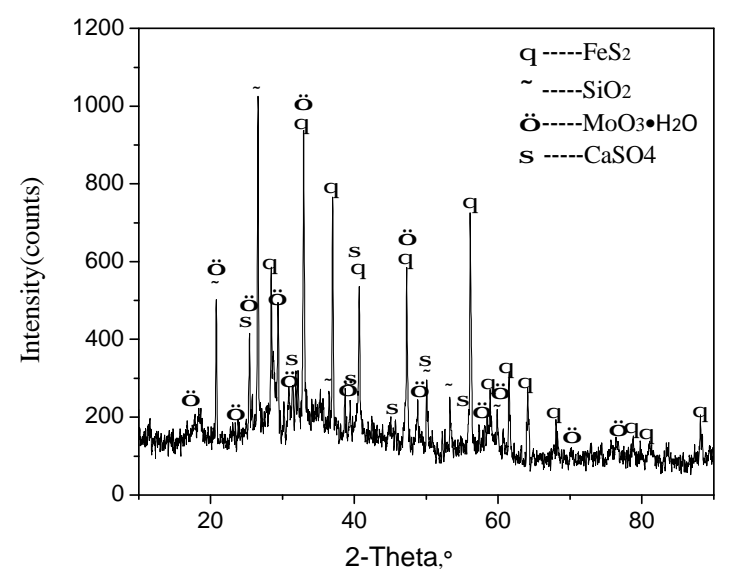

Fig. 5 XRD pattern of the acid leach residue

And in the process, $80 \%$ sulfide was oxidized to sulfate. The X-ray diffraction spectrum of the acid leach residue shown in Fig. 5 indicates that the amorphous phase molybdenum disulfide $\left(\mathrm{MoS}_{2}\right)$ in the Mo-Ni ore had changed crystalline phase to $\mathrm{MoO}_{3} \cdot \mathrm{H}_{2} \mathrm{O}$ in the pressure leaching process.

\section{Conclusions}

Oxygen pressure conditions, considerable molybdenum and almost all the nickel were extracted into solution in the leaching process. With leaching time for $3 \sim 4 \mathrm{~h}$, temperature at $150^{\circ} \mathrm{C}$, liquid-to-solid ratio of $2 \mathrm{~mL} \cdot \mathrm{g}^{-1}$, mineral granularity of $0.074 \mathrm{~mm}$, oxygen partial pressure of $0.4 \sim 0.5 \mathrm{MPa}$ without other reagent, molybdenum leaching percentage can be over $80 \%$ and nickel leaching percentage can be more than $97 \%$. Furthermore, about $80 \%$ sulfur in the Mo-Ni ore has been transformed into sulfuric acid, which provided sufficient acid for the leaching of nickel and molybdenum. Then yielding the leach liquor of $10 \sim 15 \mathrm{~g} / \mathrm{L} \mathrm{H}_{2} \mathrm{SO}_{4}$.

\section{Acknowledgements}

This work was financially supported by the National Natural Science Foundation of China (51474115) and Yunnan Province Applied Foundation Research Programs of China (2014FB126).

\section{References}

[1] Jingwen Mao, Bernd Lehmann, Andao Du, Guangdi Zhang, Dongsheng Ma, Yitian Wang: Economic Geology, 2002,97(5), p1051-1061.

[2] FAN D L, ZHANG T, JIE Y, PAAVA J, KRIBEK B, DOBES P, VARRIN I, ZAK K. : Ore Geology Reviews , 2004, 241(1-2), p103-120.

[3] BAO Zheng-xiang: Geology and Mineral Resources Research, 1990, 3, p49-62.

[4] WANG Xu-wen, PENG Jun, WANG Ming-yu, Ye Pu-hong, The role of CaO in the extraction of $\mathrm{Ni}$ and Mo from the Mo-Ni ore by calcification roasting, sulphation roasting and water leaching[J]. International Journal of Mineral Processing, 2011, 100, p130-135.

[5] WANG Ming-yu, WANG Xue-wen, LIU Wan-li: Hydrometallurgy, 2009, 97, p126-130.

[6] LIU Wei-ping, XU Hui, YANG Xi-yun, SHI Xi-chang: Minerals engineering, 2011, 24, p1580-1585.

[7] ZHAO Zhong-wei, Li Jiang-tao, CAO Cai-fang, HUO Guang-sheng, ZHANG Gang, Li Hong-gui: Hydrometallurgy, 2010, 103, p68-73. 
[8] Wang Ming-shuang, Wei Chang, Fan Gang, Deng Zhi-gan, Wang Si-fu, Wu Jun: Rare Metals, 2013, 32(2), p208-212.

[9] CHEN Jia-wu, GAO Cong-jie, ZHANG Qi-xiu, XIAO Lian-sheng: Transactions of Nonferrons Metals Society of China, 2010, 21, p135-140.

[10] STEINER M, WALLIS E, ERDTMANN B D, ZHAO Y L, YANG R D: Palaeogeography, Palaeoclimatology, Palaeoecology, 2001, 169, p165-191.

[11] KONONOVA O N, KHOLMOGOROV A G, KACHIN S V, KALYAKINA O P, SADOVSKAY E V: Hydrometallurgy, 2003, 68, p83-87. 